\title{
Design Improvement of Cutting Part in Tunneling Shield
}

\author{
Anton Letopolsky ${ }^{1}$, Pavel Korchagin ${ }^{1}$, and Irina Teterina ${ }^{1, ~ *}$ \\ ${ }^{1}$ Siberian State Automobile and Highway University (SibADI), 644080, Omsk, Mira Ave, 5, Russia
}

\begin{abstract}
The article presents a variant for improving the design of a working body of a tunneling shield, its cutting part to be more precise. The working body of the tunneling shield has been improved with the changes in the design of a rotor working surface. The theoretical studies aimed at determining the strength characteristics of the proposed rotor design have been carried out. The proposed rotor model has been visualized with the use of the T-Flex CAD software. On the basis of the results obtained in the course of the theoretical research, a comparative analysis of the strength characteristics of the main and improved model of the cutting working body of the tunneling shield have been made. The studies carried out at TFlex CAD confirmed the working capacity of the improved design of the tunneling shield working body. The strength of the rotor has been determined as a result of the studies carried out. The maximum values of the displacement module is $2.875 \mathrm{E}-05 \mathrm{~m}$, the equivalent stresses are 29.47 $\mathrm{MPa}$, a reserve coefficient on equivalent stresses is $9.446 \mathrm{E} 06$.
\end{abstract}

\section{Introduction}

A tunneling shield is a prefabricated mobile metal structure, the function of which ensures the safety of tunneling works and the assembly of the permanent support (lining) of the tunnel [1]. A tunneling shield is essential in construction works for building tunnels of any purpose. The machine is used for underground mining and for construction of tunnels of various purposes [2]. The diameter of the tunnels obtained with the tunneling shield may vary from 1 to 19 metres.

The use of this machine makes it possible to implement the trenchless method of pipeline with a mechanical method in both watered and dry soils without a human involvement in a bottom [3]. The trenchless method of pipeline is considered promising and can simultaneously achieve the following:

1. Construction of underground utility lines (water, heat, gas, sewage);

2. Construction of electric cable cases [4];

3. Construction of runways, railways and motorways;

4. Construction of feeding structures to the objects located at the centre of the water body [1.4];

5. Original support for large tunnels [4].

\footnotetext{
* Corresponding author : iateterina@mail.ru
} 
Despite promising trenchless method, the issues, related to the redesign of the working bodies of the tunneling shield in order to improve productivity and safety as well as to reduce annual costs and benefits, are still relevant.

\section{Purpose of research}

The purpose of this study is to improve the design of the cutting part of the working body of the tunneling shield during the working process in areas with incased hardness in order to improve productivity and efficiency.

\section{Research material and methods}

The optimal speed and parameters of tunneling can be achieved by selecting an appropriate working body, which at equal conditions must be aimed towards the type of soil in which the work is to be carried out [5]. Figure 1 shows a general view of the cutting part of the working body of the tunneling shield.

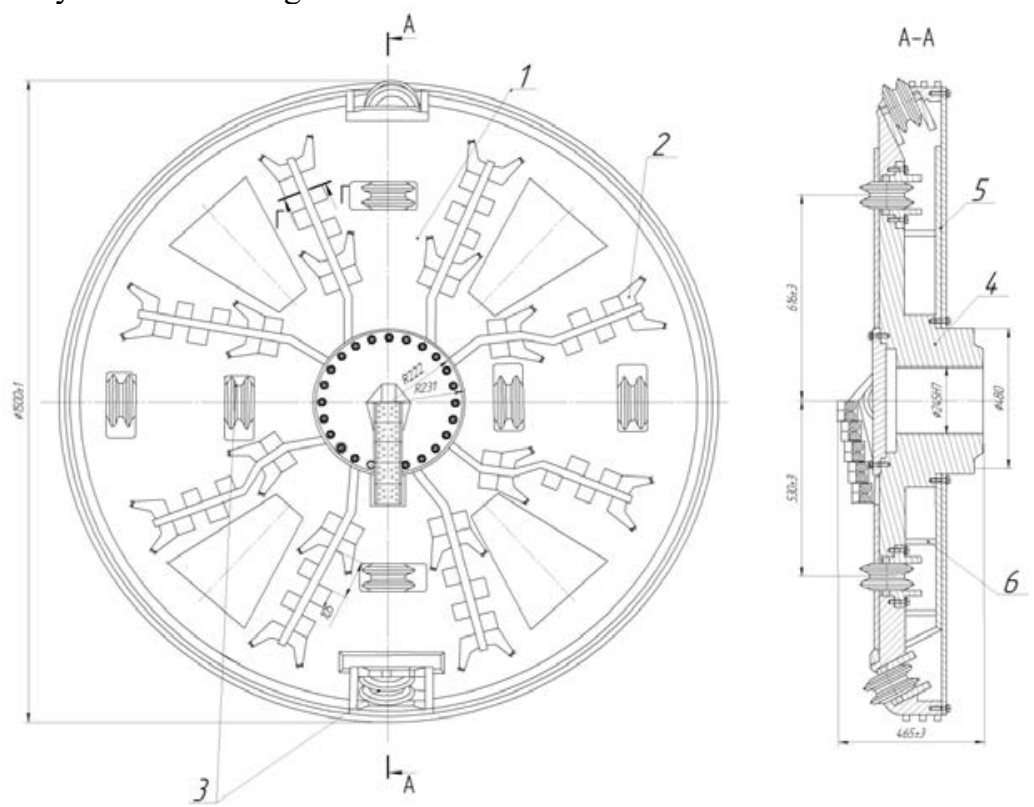

Fig. 1. Cutting head of the tunneling shield.

The cutting element of the working body of the tunneling shield consists of a cutting head of the shield (1), cutting elements (2) which are arranged in the form of rockers along the whole area of the working surface, roller cutters (3), a shell (4), a rear cover (5) and rear cover supports (6).

The design of the basic working body is improved by the fact that the central element of the working surface of the rotor is projected. A borer [6] is fixed to the working surface in the form of a crosspiece with cutting elements arranged at the ends of it. The cutting elements arranged at an angle to each other are in the form of the hard alloy inserts. Each cutting element on the working surface of the rotor is in the form of a rocker. The remaining working surface of the rotor is provided with the slotted tools. 
In order to confirm the efficiency of the proposed idea of the cutting part of the tunneling shield, some calculations are carried out to determine the movement forces of the shield, as well as the calculations aimed at determining power and torque.

The forces which the tunneling shield overcomes during the movement are the resistance force to the penetration of the head into the bottom, the friction force on the rock with the outside surface of the shell, the friction force of the inside surface of the shell on the erected lining, and the part of the tunneling complex that moves with it.

Under these conditions, the rated force of the shield shift is determined with the formula $[7,8]$.

$$
F r=F_{1}+F_{2}+F_{3}+F_{4}
$$

where $F_{1}$ is the frontal resistance of the head of the shield, $\mathrm{kH} ; F_{2}$ is the resistance to the shift along the outside surface of the shield shell, $\mathrm{kH} ; F_{3}$ is the resistance to the shift along the inside surface of the shield cover, $\mathrm{kH} ; F_{4}$ is the displacement force of a part of the tunneling technological complex, $\mathrm{kH}$.

$$
F_{1}=p_{s p} \cdot D \cdot \pi
$$

where $p_{s p}$ is a specific penetration force equal to $12001600 \mathrm{kH} / \mathrm{m}^{2}$ in loams; $D$ is the shield diameter, $\mathrm{m}$.

$$
F_{2}=f_{m} \cdot\left[2 \cdot(1+\xi) \cdot q \cdot L_{m} \cdot D+G\right],
$$

where $f_{m}$ is the coefficient of soil friction on steel, $0.80-0.95 ; \xi$ is a lateral pressure coefficient of rock (clay soils depending on density and composition, $\xi=0.300 .85$ ); $q$ is the intensity of vertical rock pressure on the shield, $\mathrm{n} / \mathrm{m}^{2} ; G$ is the mass of the shield, $\mathrm{t}$.

If the depth of the tunnel is relatively large when a collapsed structure is formed above the shield, the intensity of the vertical rock pressure [9]

$$
q=\gamma \cdot h
$$

where $\gamma$ is the average mass of the rock above the shield, $\mathrm{t} / \mathrm{m}^{3} ; h$ is the height of the collapse vault, $\mathrm{m}$.

The height of the roof arch is determined with the formula $[10,11]$

$$
h=\frac{B}{2 f},
$$

where $B$ is a span of the pressure arch, $\mathrm{m}$; $f$ is a coefficient of rock hardness according to Professor M.M. Protodiakonov's scale.

The span of the pressure arch is determined according to Professor M.M. Protodiakonov's theory [12]

$$
B=D+2 \cdot D \cdot \tan \left(45-\frac{\varphi}{2}\right),
$$

where $\varphi$ is the angle of internal friction, deg.

In order to press the concrete mixture under the shield shell in the longitudinal direction at the initial shift of the shield, the value of the force will be maximum. The force value is determined by considering the equilibrium of the elementary volume of the mixture between the formwork and the shield shell under the pressure produced by a pressure ring.

The formula [13] is applicable in the case of the use of a shifting sectional formwork

$$
F_{3}=\rho_{0} \cdot \pi \cdot R \cdot(R-r) \cdot\left(1-\exp \cdot\left(-\frac{2 \cdot \mu \cdot f_{2} \cdot L}{R-r}\right)\right)
$$

where $\rho_{0}$ is the axial pressure on the concrete mixture under the end of the pressing ring, $\mathrm{H} / \mathrm{m}^{2} ; R$ is an inside radius of the shield shell, $\mathrm{m} ; r$ is an outside radius of the 
formwork, $\mathrm{m} ; \mu$ is a lateral pressure transmission coefficient in the concrete mixture; $f_{2}$ is a metal friction coefficient on the concrete mixture; $L$ is the length of the space under the shield shell filled with concrete mixture, $\mathrm{m}$.

$$
F_{4}=G_{1} \cdot f_{2} \cdot k,
$$

where $G_{1}$ is a mass of the part of the tunneling complex moving along with the shield, t;

$k$ is a coefficient considering a possible local resistance to the movement of the tunneling complex elements.

The power required for the development of the soil depends on a defined productivity of the shield, its diameter and the resistance of the soil to the destruction.

For shields with a cutter wheel the power $(\mathrm{kW})$ spent on soil development $[14,15]$

$$
N=\frac{2 \cdot \pi \cdot M_{t o r} \cdot n_{t f}}{\eta},
$$

where $M_{t o r}$ is a torque on a shaft of a cutter wheel, $\mathrm{kH} / \mathrm{m} ; n_{t f}$ is a frequency of a rotational speed of a cutter wheel, $\mathrm{c}^{-1} ; \eta$ is a drive efficiency equal to 0.85-0.9.

The torque of a cutter wheel $[9,14]$

$$
M_{t o r}=(1.2 \div 1.5) \cdot \frac{\pi}{1.2} \cdot f_{f r 1} \cdot p_{1} \cdot D_{e x}^{3},
$$

where the multiplier 1.2 considers the costs for cutting and loading the soil (refers to the sands development); 1.5 are for clays and loams; $f_{f r 1}$ is a coefficient of soil friction on steel; $p_{1}$ is a horizontal soil pressure, $\mathrm{MPa} ; D_{e x}^{3}$ is a diameter of a cutter wheel, $\mathrm{m}$.

\section{Research findings and discussions}

The theoretical research aimed at determining the strength characteristics of the proposed design of a working body of a tunneling shield was carried out in the T-Flex CAD software product. The applied automated design system has sufficient means to develop projects of any difficulty, besides it combines a wide range of parametric possibilities for $2 \mathrm{D}$ and $3 \mathrm{D}$ modelling.

The following algorithm is included in the strength calculations:

1. Set the material and determine the type of attachment for the cutting part of the tunneling shield (heat-resistant stainless steel of $20 \times 13$ chromium grade, which is distinguished with its resistance to mildly aggressive media, is used for the product).

2. Set the load (the forces arising on the cutters of the shield are determined with the formula (2); the forces are applied to the attachment points of the cutters on the rotor of the tunneling shield; the forces are directed along the axes of the cutters).

3. Construct a mesh in a solid that breaks the model into smaller segments.

4. Calculate the displacement module.

5. Calculate the equivalent stresses.

6. Calculate the reserve coefficient for the equivalent stresses.

Figure 2 shows the visualization of the theoretical studies results to determine displacements in the structure of a working body of the tunneling shield in a basic (2a) and improved parts (2b). 
Diplacement, module, im
Dikplacement scale: 2655.36

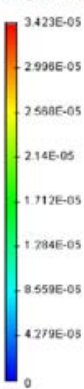

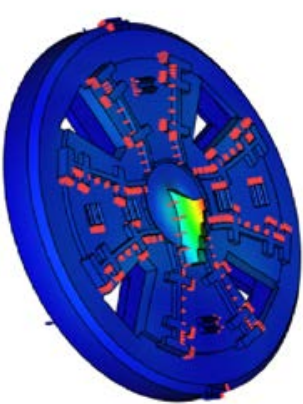

a.

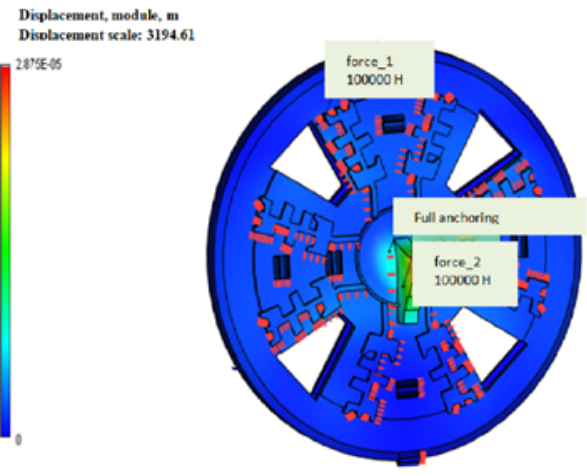

b.

Fig.2. Study of displacements in the structure of the cutting element of the working body: a. basic design; b. improved design.

The results of the studies showed that the minimum movements in both the basic and the proposed model occur at $0 \mathrm{~mm}$. At the same time, the maximum movements in the basic model of the cutting element of a working body occur at $3.423 \mathrm{e}-05 \mathrm{~m}$, in the developed - at $2.875 \mathrm{e}-05 \mathrm{~m}$. Figure 3 presents the results of the studies aimed at determining possible stresses in the design of the cutting element of a working body $[16,17]$.

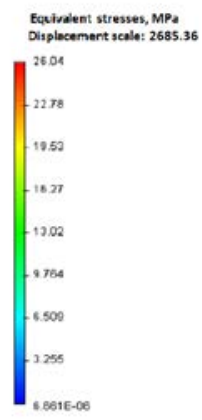

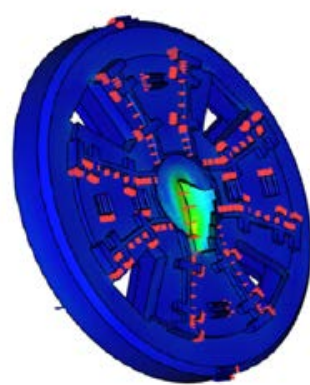

a.

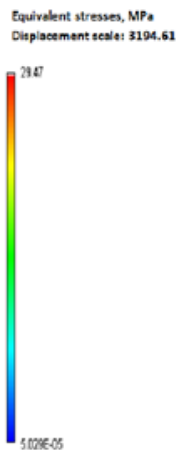

б.

Fig. 3. Study of stresses in the structure of the cutting element of the working body: a. - basic design; b. - modernized design.

The studies have concluded that the minimum values in the basic model design are equal to $6.661 \mathrm{E}-06 \mathrm{MPa}$ and the maximum values are equal to $26.04 \mathrm{MPa}$. In the proposed model the minimum is $5.029 \mathrm{E}-05 \mathrm{MPa}$ and the maximum is $29.47 \mathrm{MPa}$.

Figure 4 presents the results of the studies aimed at determining a reserve coefficient in the cutting element of the working body in the basic and improved models [18.19]. 


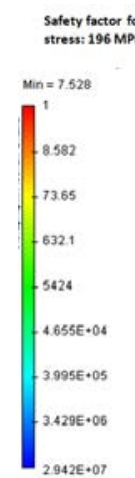

Safety factor for equivalent voltages Maximum allowable

$\operatorname{Min}=7.528$

8.582

3.65

532.1

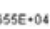

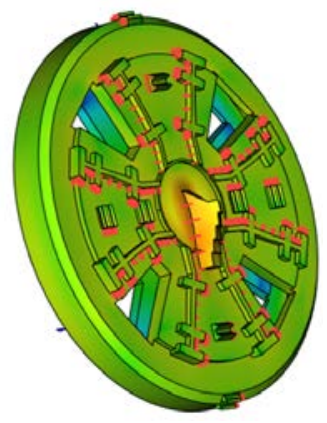

a.

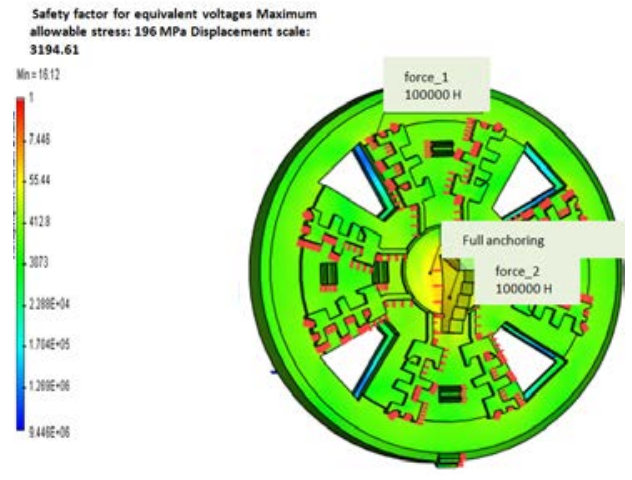

6.

Fig. 4. Study of strength in the structure of the cutting element of the working body: a. basic design; b. modernized design.

A reserve coefficient for the equivalent stresses of the basic model is 7.528 MPA minimum, the maximum values are $2.942 \mathrm{E} 07$. The safety factor of a improved design is 1 with the minimum values and 9.446E 06 with the maximum values.

\section{Conclusion}

The article proposes the model of the structural modifications in a cutting part of a tunneling shield. The calculations carried out using T-Flex CAD software proved the working capacity of a cutting wheel. The stresses obtained during the calculation of a rotor design does not exceed the accepted values of yield strength of steel. The results of the research led to the conclusion that the proposed model of the design of a working body of a tunneling shield was used reasonably and efficiently. The results of the calculations presented need to be further validated in the course of the pilot studies.

\section{References}

1. A.N. Pankratenko, Modern technologies for the construction of micro-tunnels and their interpretation, Mining information and analytical bulletin (scientific and technical journal), No. S1, pp. 479-487 (2018)

2. D.N. Nesteruk, A.V. Kosovets, The results of the market analysis of the use of shield tunneling complexes in the Russian Federation, Concept scientific and methodological electronic journal, No. 6, pp. 111-115 (2015)

3. C. Zhou, L.Ding, Y. Zhou, M.J. Skibniewski, Visibility graph analysis on time series of shield tunneling parameters based on complex network theory, Tunnelling and Underground Space Technology, № 89, Pp. 10-24 (2019)

4. Korzun, N.L., Balkanov A.A. The proof for the use of microtunnelling for laying engineering networks in urbanized areas // Izvestia vuzov. Investments. Construction. Real estate, No. 1(6), S. 50-66 (2014)

5. L. Liu, Q. Shen, Y. Zhao, Correlation between railway subgrade settlement and shield tunneling construction // International Journal of Mechatronics and Applied Mechanics. No.5, pp. 57-61 (2019) 
6. J. Li, SJ. Shao, S. Shao, Collapsible characteristics of loess tunnel site and their effects on tunnel structure Tunn Undergr Space Technol. No. 83, pp. 509-519 (2019)https://doi.org/10.1016/j.tust.2018.08.035

7. P.A. Korchagin, A.B. Letopolsky, I.A. Teterina, Results of studies for the modernized equipment of a pipe layer, Bulletin of the Ural State Mining University. No. 1 (53), pp. 96-102 (2019) https://doi.org/10.21440/2307-2091-2019-1-96-102

8. Zhuravlev A.E. Influence of the tunneling shield on the deformation of the soil body and the earth surface during the construction of microtunnels in unstable soils. Surveying bulletin, No. 3 (112), pp. 51-55 (2016)

9. A.B. Letopolsky, P.A. Korchagin, I.A. Teterina, The design of the guide frame of the tunneling shield for laying communications under the riverbed, IOP Conference Series: Materials Science and Engineering. (ICMTMTE 2019), C. 044028 (2020) https://doi.org/10.1088/1757-899X/709/4/044028

10. I.L. Nikiforova, Analytical and experimental method for calculating the displacement of the earth surface during tunneling with shield complexes, Surveying and subsoil use. No. 1 (75), pp. 37-39 (2015)

11. E.M. Naumenko, Methods for determining soil subsidence by graphic and analytical method during shield tunneling, Undergrounds and tunnels. No. 3. pp. 30-33. (2018)

12. S Li, H Liu, L Li, Q Zhang, K. Wang, K. Wang, Large scale three-dimensional seepage analysis model test and numerical simulation research on undersea tunnel, Appl Ocean Res. No. 59, 510-520 (2016) https://doi.org/10.1016/j.apor.2016.07.013

13. A.S Khoroshev, I.V. Vasyukov, S.A. Zemlyanoy, Experimental investigation of possible use of ferroprobe sensors in advanced exploration system of tunneling shield , International Russian Automation Conference, RusAutoCon (Proceedings - 2019), C. 8867622 (2019)

14. O.V. Telegina, Analysis of the stressed state around the shell of a cutting wheel of the tunneling shield of non-circular cross-section, Mining information and analytical bulletin (scientific and technical journal), No. 9, pp. 98-101 (2014)

15. P. A. Korchagin, A. B. Letopolsky, I. A. Teterina, Result of research of working capability of refined pipe layer equipment, Aviamechanical engineering and transport (AVENT 2018), No. 158, pp. 416-420 (2018)

16. V.A. Ilichev, N.S. Nikiforova, A.V. Konnov, D.V. Emelianov, Reconstruction of communications by microtunneling on the territory of cultural heritage objects, Zhilishchnoe stroitelstvo, No. 6, pp. 15-20 (2020) https://doi.org/10.31659/00444472-2020-6-15-20

17. Liu Hengyu, Wang Binglong, Zhou Shunhua, Shield Tunneling under Railway Station Throats in Soft Soil Areas: A Case Study, Advances in Civil Engineering, Article ID 2080678, P. 13 (2020) https://doi.org/10.1155/2020/2080678

18. Qiu Junling, Lu Yuquan, Lai Jinxing, Zhang Yuwei, Yang Tao, Wang Ke, Experimental study on the effect of water gushing on loess metro tunnel, Environmental Earth Sciences, No. 79, P.261 (2020) https://doi.org/10.1007/s12665020-08995-4

19. Pashkin E.M., Mazein S.V. About the methods of diagnostics of heterogeneous engineering and geological conditions during shield tunneling of the undergrounds, Undergrounds and tunnels, No. 1-2, pp. 24-27 (2017) 